\title{
Análise multitemporal da regeneração natural da candeia após ocorrência de incêndio florestal
}

\section{Multitemporal analysis of natural regeneration of Candeia after occurrence of forest fire}

\author{
Ivy Mayara Sanches de Oliveira ${ }^{1}$; Alex Donizeti Sales ${ }^{2}$, Eduarda Martiniano de Oliveira Silveira ${ }^{3}$; Fausto Weimar \\ Acerbi Júnior ${ }^{4}$; José Marcio de Mello ${ }^{5}$
}

Resumo: Os sensores de satélites têm a capacidade de fornecer informações sobre regiões afetadas pela atividade do fogo, sendo uma ferramenta eficiente para a detecção e quantificação destas áreas. Objetivou-se avaliar o comportamento da regeneração natural da candeia Eremanthus incanus (Less.) Less, após a ocorrência de incêndio florestal por meio do índice de vegetação da diferença normalizada (NDVI) de forma a identificar a capacidade de resiliência da espécie. O incêndio ocorreu em 1999, ao lado do Parque Nacional da Serra do Cipó no município de Morro do Pilar, Minas Gerais. Foi selecionada uma série temporal de quatro imagens adquiridas entre os anos de 1999 a 2005 do satélite Landsat (TM e ETM ${ }^{+}$). Foram geradas as imagens NDVI e em seguida foram obtidos seus valores de reflectância nas diferentes datas para analisar o comportamento espectral das áreas em regeneração. Posteriormente esses parâmetros foram utilizados para analisar as alterações na cobertura vegetal. Ao comparar os valores de NDVI antes e pós-incêndio, observou-se que num período de 6 anos a candeia apresenta valores de reflectância próximos àqueles encontrados antes do incêndio, o que sugere que a cobertura vegetal está num estágio similar à antes da ocorrência do fogo. $\mathrm{O}$ índice aplicado mostrou-se eficiente na análise da capacidade de resiliência da espécie após o fogo.

Palavras-chave: Sensoriamento remoto, NDVI, detecção de mudanças.

\begin{abstract}
Satellite sensors have the ability to provide information on areas affected by fire activity, being an efficient tool for detection and quantification of these areas. The aim of this study was to analyze the natural regeneration pattern of the Eremanthus incanus (Less.) Less, after the occurrence of forest fire, using the normalized difference vegetation index (NDVI) in order to identify its resilience capacity. The fire occurred in 1999, next to the Serra do Cipó National Park in Morro do Pilar city, Minas Gerais. A time series of four Landsat (TM e ETM ${ }^{+}$) images acquired between the years 1999-2005 were selected. The NDVI images were generated and their reflectance values were obtained at the different dates to analyze the spectral pattern of regenerating areas. Later, these parameters were used to analyze the vegetation cover changes. Comparing the NDVI values before and after the fire, it was observed that, over a period of 6 years the reflectance values were close to those found before the fire, which suggests that the vegetal cover is at a similar stage before the fire occurrence. The applied index proved to be efficient in the analysis of the species capacity of resilience after the fire occurrence.
\end{abstract}

Key words: Remote sensing, NDVI, change detection.

\footnotetext{
*Autor para correspondência

Recebido para publicação em 15/02/2017; aprovado em 10/05/2017

${ }^{1}$ Mestranda em Engenharia Florestal, Universidade Federal e Lavras, Lavras; (35) 991612640, ivymayara07@gmail.com

${ }^{2}$ Engenheiro Florestal, Universidade Federal de Lavras, asales.engflo@gmail.com

${ }^{3}$ Doutoranda em Engenharia Florestal, Universidade Federal de Lavras, dudalavras@ hotmail.com

${ }^{4}$ Prof. Dr. do curso de Engenharia Florestal, Universidade Federal de Lavras, fausto@ dcf.ufla.br

${ }^{5}$ Prof. Dr.do curso de Engenharia Florestal, Universidade Federal de Lavras, josemarcio@dcf.ufla.br
} 


\section{INTRODUÇÃO}

A candeia Eremanthus incanus (Less.) Less é uma espécie florestal nativa comumente encontrada nas regiões nordeste (Bahia) e sudeste (Minas Gerais) do Brasil, nos domínios do Cerrado, Caatinga e Mata Atlântica. Pertence à família Asteraceae e ao gênero Eremanthus que possui 22 espécies conhecidas. Segundo Scolforo et al. (2012) esta é uma das espécies de candeia de maior ocorrência no estado de Minas Gerais.

Essa espécie, quando adulta, tem altura média entre 5 e $7 \mathrm{~m}$, diâmetro médio entre 10 e $12 \mathrm{~cm}$. A candeia torna-se importante para o pequeno e médio produtor por ser uma fonte de renda extra, uma vez que é utilizada para a produção de moirões de longevidade superior a 30 anos, e também por se desenvolver em altitudes elevadas $(550$ e $1.700 \mathrm{~m})$ e em sítios pouco férteis, onde outras culturas florestais e agrícolas não se desenvolveriam (SCOLFORO et al, 2012).

O município de Morro do Pilar, localizado em Minas Gerais, apresenta extensas áreas com povoamentos naturais de Eremanthus incanus (Less.) Less, devido as características edafoclimáticas do local que favorecem o predomínio dessa espécie em larga escala. Contudo, em outubro de 1999 a região foi atingida por um incêndio de elevadas proporções afetando cerca de 100 ha de candeal nativo.

Pereira (2016), afirma que as geotecnologias surgem como um importante recurso de subsídio para a identificação das queimadas e incêndios, permitindo localizar, quantificar e realizar estudos de análises espaço-temporais das áreas onde ocorrem incêndios florestais. Uma ferramenta importante para essa identificação é o sensoriamento remoto que permite cruzar informações georreferenciadas, permitindo quantificar e localizar os focos de calor (TOMZHINSKI et al., 2011).

Os satélites da série Landsat, têm sido utilizados nos estudos com detecção de queimadas (SILVA; BAPTISTA, 2015; FERNANDES et al, 2016). As bandas do visível (RGB - Red Green Blue) e infravermelho próximo, designados para o estudo de vegetação, possibilitam a detecção de queimadas e a avaliação do estado da vegetação através de índices de vegetação.

Silva et al. (2009) mencionam que os índices de vegetação foram desenvolvidos com a finalidade de reduzir o número de parâmetros presentes nas medidas multiespectrais, constituindo uma importante estratégia para o monitoramento das alterações, naturais ou não, nos ecossistemas. Estes índices utilizam especialmente as regiões do visível e infravermelho próximo baseando-se no fato de que a energia refletida nessas regiões do espectro é diretamente relacionada à atividade fotossintética da vegetação (PONZONI; SHIMABUKURO, 2010).

O Índice de vegetação por diferença Normalizada (NDVI), derivado dos comprimentos de onda do vermelho e infravermelho próximo, representam uma importante fonte de análise da estrutura da cobertura do solo e de mudanças temporais (WULDER et al., 2006). Este índice tem sido muito utilizado no estudo da dinâmica da vegetação devido a sua simplicidade e correlação com variáveis ecológicas de nteresse (QUN; HUIZHI, 2013; ACERBI JUNIOR et al., 2015).

O NDVI baseia-se na alta absorção de radiação eletromagnética pela clorofila que é verificada na região espectral do vermelho e na alta reflectância, explicada pela estrutura interna das folhas, na região do infravermelho próximo (NIR), podendo saturar em coberturas vegetais densas com valores de índice de área foliar elevados. $\mathrm{O}$ valor de NDVI varia entre -1 a 1 , quanto mais próximo de 1 maior a densidade da cobertura vegetal. Valores próximos a 0 representam superfícies não vegetadas (ROUSE et al.,1973).

Segundo Magalhães (2014), o NDVI é o índice mais conhecido e utilizado para avaliações de queimadas, desmatamentos e regeneração natural, pois por meio de séries temporais, este índice permite a quantificação das mudanças da vegetação em relação à distribuição (MARTINS et al., 2014), fenologia (HERMUCHE E FELFILI., 2011) e produtividade (ALMEIDA et al., 2015).

Para que ocorra regeneração natural em uma área degradada, por um incêndio, por exemplo, são necessárias algumas condições, como o cessar dos processos causadores da degradação, a existência de fonte de propágulos (banco de sementes do solo, chuva de sementes), presença de dispersores e boas condições microclimáticas e edáficas para o estabelecimento e ocorrência do ciclo de vida completo das plântulas (FARIA et al., 2001). Os estudos de regeneração são fundamentais para o entendimento do estabelecimento e evolução de um ecossistema florestal (NAPPO et al., 1999) e podem ser usados como indicadores da capacidade de resiliência de ecossistemas florestais (RODRIGUES; LEITÃO-FILHO, 2000).

Tendo em vista a grande importância econômica da candeia (seus produtos alcançam preços relativamente altos no mercado) e seus múltiplos usos (madeira, óleo e etc), justifica-se a importância de se conhecer sua capacidade de resiliência após um distúrbio.

Em estudos de mapeamento e dinâmica da cobertura vegetal, o uso de produtos do sensoriamento remoto permitem a extração de informações que subsidiam monitoramentos e análises do estado da cobertura vegetal após a ocorrência de alguma perturbação natural ou antrópica. Esse tipo de avaliação é mais prático e viável uma vez que não é necessária a medição das árvores na região afetada, processo que pode ser oneroso e caro. Através dos níveis de reflectancia das folhas, é possível avaliar se região conseguiu se recuperar do distúrbio e estimar o tempo necessário para essa recuperação.

Diante do exposto, objetivou-se avaliar o comportamento da regeneração natural da candeia após a ocorrência de incêndio florestal por meio de uma análise multitemporal de imagens de satélite de forma a identificar a capacidade de resiliência da espécie.

\section{MATERIAL E MÉTODOS}

\section{Descrição da área de estudo}

O município de Morro do Pilar possui 476,22 km² e está localizado na região central do estado de Minas Gerais. A área de estudo (Figura 1) com coordenadas centrais de $19^{\circ} 19^{\prime} 47.01^{\prime \prime} \mathrm{S}$ de latitude e $43^{\circ} 26^{\prime} 59.55^{\prime \prime} \mathrm{W}$ de longitude, faz divisa com o Parque Nacional da Serra do Cipó e está inserida na propriedade denominada Fazenda dos Coelhos. No mês de outubro de 1999, ocorreu nessa região um incêndio em elevadas proporções atingindo um total de 100 ha de candeia Eremanthus incanus (Less.) Less. 
Figura 1. Distribuição da candeia no Estado de Minas Gerais, local do incêndio ao lado do Parque Nacional da Serra do Cipó.

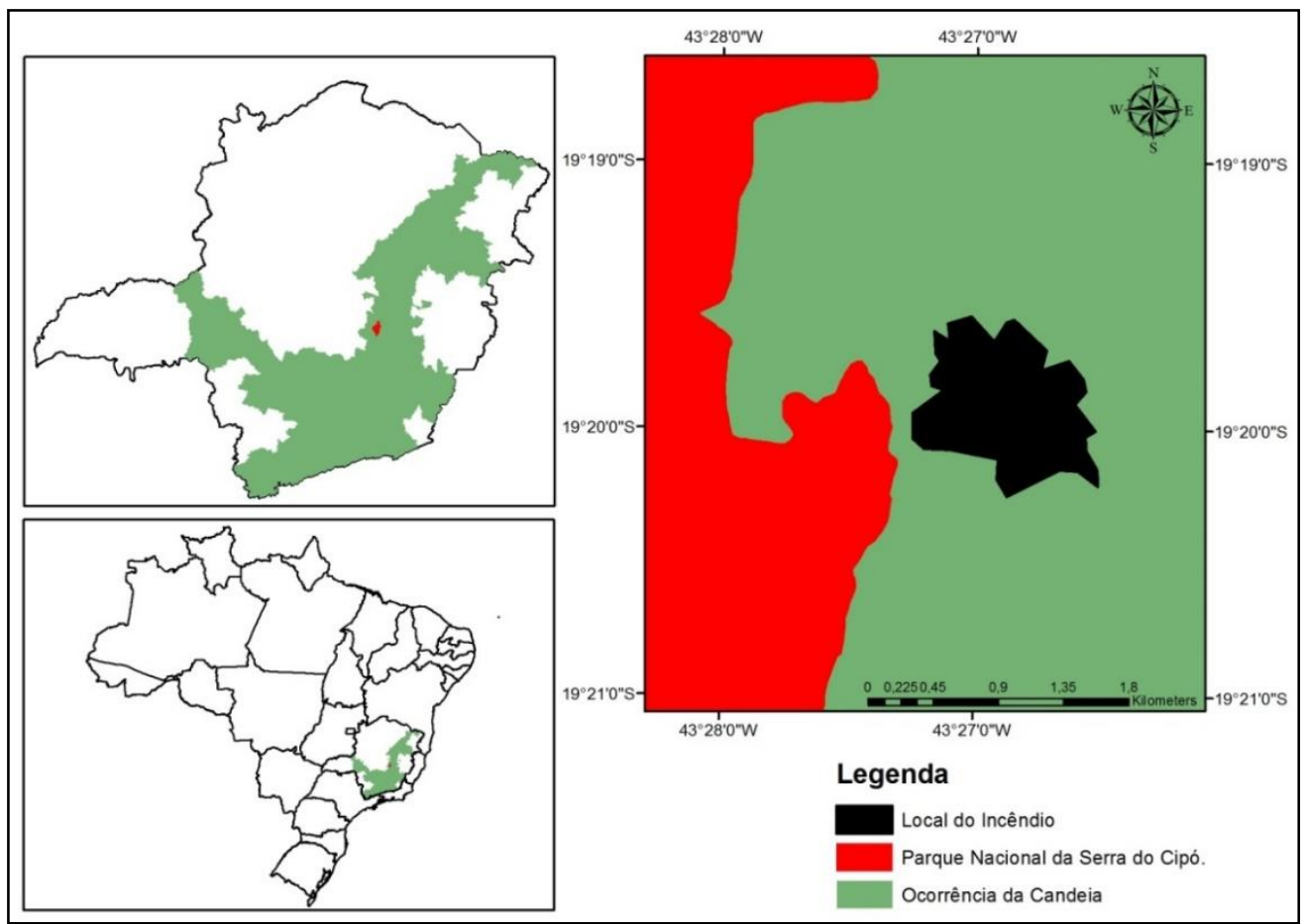

Fonte: Scolforo et al. (2012)

\section{Base de dados}

Para realização da análise multitemporal foram obtidas imagens do Serviço Geológico dos Estados Unidos (USGS), dos satélites Landsat 5 (TM) e Landsat 7 (ETM+), com resolução espacial de 30 metros, em um período de 6 anos. As imagens foram adquiridas com os pré-processamentos a nível do subproduto Landsat Surface Reflectance, eliminando a necessidade de novas correções, uma vez que essas imagens possuem correção geométrica e valores de reflectância a nível do solo. As datas e informações das imagens estão apresentadas na Tabela 1 .

Tabela 1. Imagens utilizadas na análise do local do incêndio ao lado do Parque Nacional da Serra do Cipó no Estado de Minas Gerais

\begin{tabular}{llllll}
\hline Satélite & Sensor & Órbita & Ponto & $\begin{array}{l}\text { Resolução } \\
\text { Espacial } \\
\text { (m) }\end{array}$ & $\begin{array}{l}\text { Data de } \\
\text { Aquisição }\end{array}$ \\
\hline Landsat5 & TM & 218 & 73 & 30 & $03 / 08 / 1999$ \\
Landsat7 & ETM $^{+}$ & 218 & 73 & 30 & $17 / 12 / 1999$ \\
Landsat5 & TM & 218 & 73 & 30 & $21 / 07 / 2000$ \\
Landsat5 & TM & 218 & 73 & 30 & $18 / 07 / 2005$ \\
\hline
\end{tabular}

No software ENVI 4.8, calculou-se o NDVI para as quatro cenas por meio da Equação 1.

$$
N D V I=\frac{(\mathrm{IVP}-\mathrm{V})}{(\mathrm{IVP}+\mathrm{V})}
$$

Em que: IVP representa o valor da refletância na banda do infravermelho próximo e $\mathrm{V}$ a refletância na banda do vermelho.

$\mathrm{Na}$ faixa espectral do vermelho, há alta absorção de energia solar devido à presença da clorofila e isso ocasiona baixa reflectância. Por sua vez, na faixa do infravermelho próximo, essa absorção é baixa e resulta em alta reflectância.
Portanto, a combinação dessas duas faixas espectrais realça áreas de vegetação, quanto maior o contraste maior é o seu vigor.

A delimitação da área de ocorrência do incêndio foi efetuada através de uma análise temporal por meio da subtração das imagens NDVI antes e após a data do incêndio, ou seja, foi gerada uma imagem NDVI para as datas de agosto de 1999 (antes do incêndio) e dezembro de 1999 (após o incêndio) e posteriormente efetuou-se a subtração das imagens, gerando a imagem chamada NDVI diferença.

A imagem NDVI diferença, destaca os pixels que sofreram mudanças entre essas datas, onde valores negativos (pixels escuros) indicam perda da vegetação, enquanto valores positivos (pixels claros) indicam ganho da vegetação (CARVALHO, 2008). Segundo Constatini et al. (2012), as imagens NDVI diferença são muito eficientes para detectar mudanças na cobertura do solo quer sejam elas desmatamentos, queimadas ou reflorestamentos.

A análise descritiva dos valores de NDVI foi feita com base nas medidas estatísticas (mínimo, média e máximo) do total de pixels da área. Sendo assim, foram extraídos os valores de refletância de todos os pixels da região de estudo e, para a geração do perfil temporal, esses valores foram exportados para o software Excel de forma a permitir a análise do comportamento da reflectância ao longo do tempo.

\section{RESULTADOS E DISCUSSÃO}

Por meio das imagens NDVI diferença foi possível delimitar a área de ocorrência do incêndio florestal e acompanhar o comportamento espectral da regeneração até o ano de 2005. As cenas do local (Figura 2) mostram a detecção da área queimada assim como evolução do processo de regeneração natural da candeia após o incêndio. 
Figura 2. Imagens RGB e NDVI da área de estudo, antes da ocorrência do incêndio (08/1999), depois da ocorrência do incêndio (12/1999), 6 anos após a ocorrência do incêndio (2005) e NDVI diferença entre as datas.

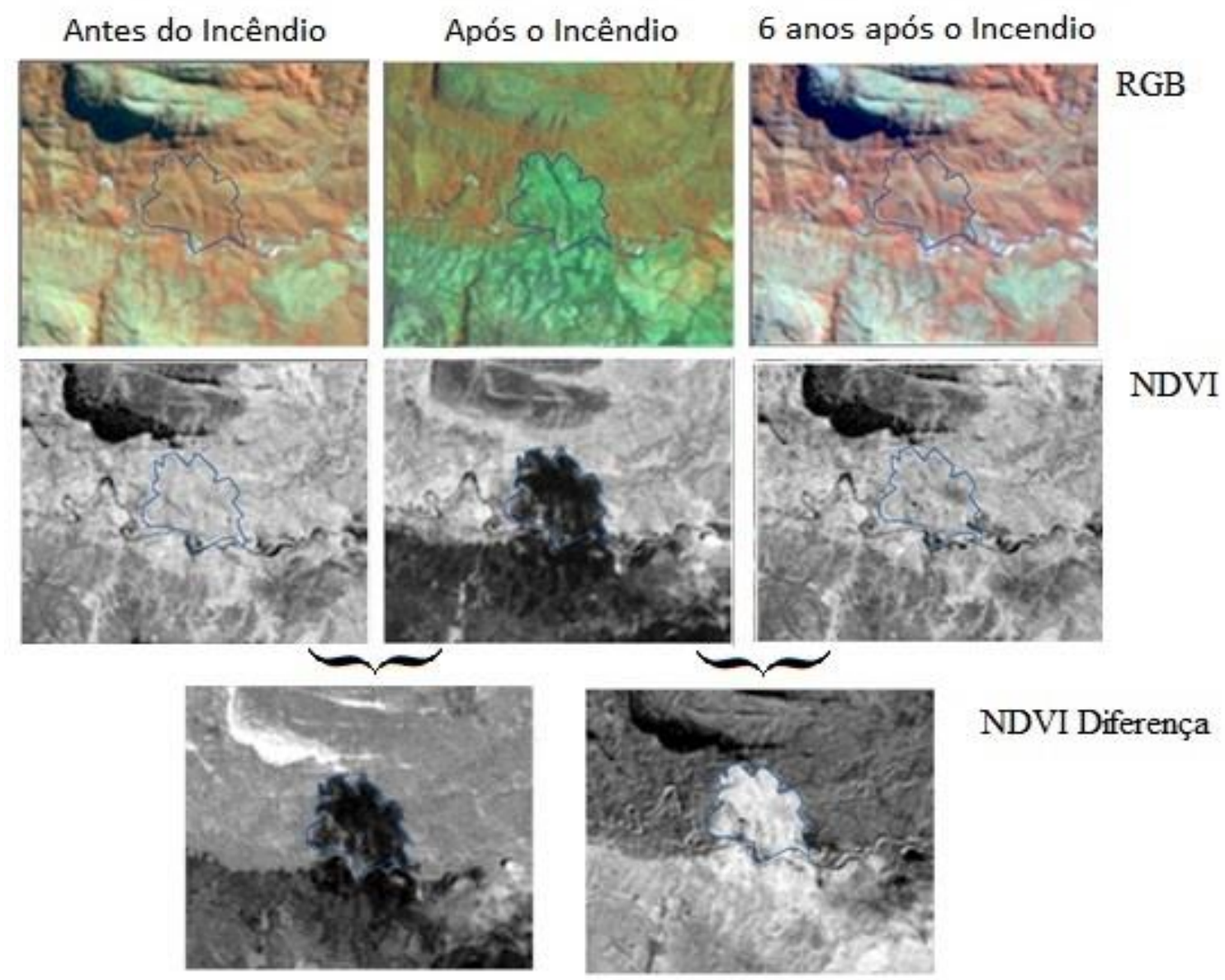

A região escura (menores valores de NDVI) representa a área afetada pelo incêndio, a região mais clara (maiores valores de NDVI) indica um aumento na vegetação, representando a área em estágio de regeneração. As estatísticas dos valores de reflectancia analisados na área de estudo, obtidos em cada data, estão apresentados na Tabela 2.

Tabela 2. Valores estatísticos de NDVI extraídos da região de ocorrência do incêndio ao lado do Parque Nacional da Serra do Cipó no Estado de Minas Gerais

\begin{tabular}{lcccc}
\hline Data & \multicolumn{3}{c}{ NDVI } \\
\cline { 2 - 5 } & Mínimo & Máximo & Médio & Desvio Padrão \\
\hline ago/99 & 0,2748 & 0,8053 & 0,6573 & 0,0616 \\
dez/99 & 0,2026 & 0,8320 & 0,3988 & 0,1434 \\
jul/00 & 0,1997 & 0,7461 & 0,4948 & 0,0997 \\
jul/05 & 0,1235 & 0,7945 & 0,6656 & 0,0684 \\
\hline
\end{tabular}

Através dos níveis de reflectancia das folhas na imagem NDVI, é possível avaliar se região conseguiu se recuperar do distúrbio e estimar o tempo necessário para essa recuperação. Analisando os valores médios de NDVI obtidos ao longo do tempo, observa-se que antes da ocorrência do incêndio florestal (agosto/1999), o valor deste índice foi de 0,6573, indicando a presença de vegetação. Após a ocorrência do incêndio (dezembro/1999), os valores foram reduzidos para 0,3988 devido à ausência de folhas e presença de cinzas em consequência da vegetação queimada. O índice sofre um aumento nos anos seguintes, devido ao início da regeneração natural. No mês de julho de 2005, aproximadamente 6 anos após o incêndio, o NDVI médio foi de 0,6656, valor muito próximo ao observado antes da ocorrência do incêndio $(0,6573)$. Essa similaridade nos mostra uma recuperação do padrão da vegetação, 6 anos após a ocorrência do incêndio.

$\mathrm{O}$ padrão de resiliência encontrado na área queimada durante o tempo avaliado é bastante coerente com as características da espécie avaliada. A Candeia, por ser uma espécie heliófila, germina somente quando sua necessidade de luz é suprida (SCOLFORO et al 2008). Dessa forma, a enorme clareira aberta pelo fogo e a presença de árvores porta sementes vizinha a área afetada, podem ter contribuído para a rápida regeneração de indivíduos após 6 anos do incêndio.

Observou-se também que as queimadas provocaram um aumento nos valores de desvio padrão do NDVI (0,0616 para 0,1434), caracterizando uma maior heterogeneidade típica de áreas que sofreram alteração na superfície terrestre.

Os valores de NDVI máximo e mínimo demonstraram ser inadequados para fazer qualquer inferência sobre o estado atual da cobertura vegetal, uma vez que esses parâmetros não apresentam uma tendência de crescimento nos anos subsequentes ao incêndio (Figura 3). Além disso, o NDVI máximo dessa data contradiz a perturbação ocorrida na área, devido ao aumento de 0,8053 em agosto/1999 para 0,8320 em dezembro/1999. Isso se deve ao tamanho da área de estudo, uma vez que esta abrange mais de mil pixels da imagem 
Figura 3. Perfil temporal da reflectância no NDVI na região de ocorrência do incêndio, ao lado do Parque Nacional da Serra do Cipó no Estado de Minas Gerais

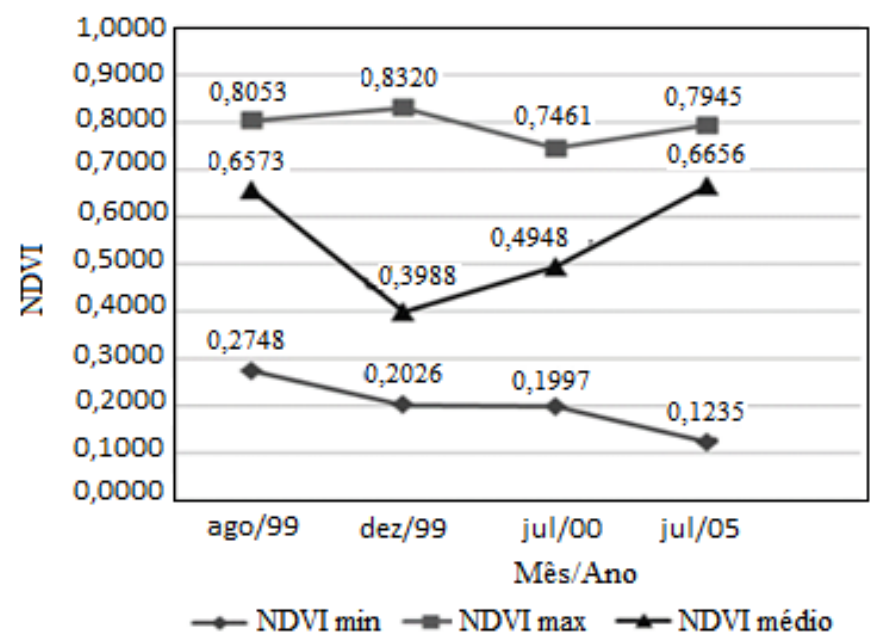

Dessa forma, os valores máximos e mínimos de NDVI podem estar sendo afetados por regiões de cinzas ou locais onde o incêndio não foi bem pronunciado, fazendo com que estes valores não sejam representativos da área queimada.

A utilização de técnicas de processamento de imagens de satélites em estudos da dinâmica da cobertura vegetal permitem a extração de informações de uma forma rápida e não onerosa. Para o caso avaliado, a ferramenta apresentou-se como uma forma prática e viável da estimativa do tempo de recuperação da vegetação, uma vez essa avaliação foi feita por meio da reflectancia das folhas e não foi necessária a medição das árvores na região afetada.

\section{CONCLUSÃO}

A análise dos valores médios do NDVI aponta que a capacidade de resiliência estimada do Candeal é de 6 anos.

A análise do comportamento dos valores de reflectância da série de imagens NDVI derivada de imagens Landsat foi capaz de captar as alterações ocorridas ao longo dos anos.

\section{REFERÊNCIAS}

ACERBI JÚNIOR, F.W.; SILVEIRA, E. M. O.; MELLO, J. M.; MELLO, C. R.; SCOLFORO, J. R. S. Change detection in Brazilian savannas using semivariograms derived from NDVI images. Ciência e Agrotecnologia, Lavras, v. 39, n. 2, p. 103-109, 2015.

ALMEIDA, A. Q; RIBEIRO, A.; DELGADO, R. C.; RODY, Y. P.; OLIVEIRA, A. S.; LEITE, F. P. Índice de Área Foliar de Eucalyptus estimado por índices de vegetação utilizando imagens TM - Landsat 5. Floresta e Ambiente, Seropédica, v.22, n.3, p.368-376, 2015.

CARVALHO, L. M. T.; SCOLFORO, J. R. S. Inventario Florestal de Minas Gerais: Monitoramento da Flora Nativa: 2005-2007. Lavras: Editora UFLA, 2008. 318p.

CONSTANTINI, M.L.; ZACCARELLI, N.; MANDRONE, S.; ROSSI, D.; CALIZZA, E.; ROSSI, L. NDVI spatial pattern and the potential fragility of mixed forested areas in
Volcanic lake watersheds. Forest Ecology and Management, Amsterdam, v. 285, p.133-141, 2012.

SILVA, S. L., BAPTISTA, G. M. M. Análise do Grau de Severidade de Áreas Queimadas na Estação Ecológica de Águas Emendadas por Meio de Dados do Landsat 8. Revista Brasileira de Geografia Física, Recife, v.8, n 2, p. 431-438, 2015.

FARIA, H. H.; SÉRGIO, F. C.; GARRIDO, M. A. O. Recomposição da vegetação ciliar integrada à conservação de microbacia. Revista do Instituto Florestal, São Paulo, v. 21, p.1-22, 2001.

FERNANDES, A. C. G., COUTINHO, M. A. N., SANTOS, V. G.; NASCIMENTO, C. R. Utilização de intervalos de índices de vegetação e temperatura da superfície para detecção de queimadas. Caderno de Ciências Agrárias, Montes Claros, v.8, p.30-40, 2016.

HERMUCHE, P. M.; FELFILI, J. M. Relação entre NDVI e florística em fragmentos de floresta estacional decidual no Vale do Paranã, Goiás. Ciência Florestal, Santa Maria, v. 21, n. 1 , p. $41-52,2011$

MAGAlHÃES, I. A. L.; XAVIER, A. C.; DOS SANTOS, A. R. Caracterização da dinâmica espectro temporal florestal e da cana-de-açucar no município de Itapemirim, ES. Geosul, Florianópolis, v. 28, n. 56, p. 183-210, 2014.

MARTINS, L. F.; DA SILVA, J. S.; HENRIQUE, M. Aplicação do índice de vegetação por diferença normalizada (NDVI) para avaliação ambiental da bacia hidrográfica do alto guariroba, Campo Grande-MS. Periódico Eletrônico Fórum Ambiental da Alta Paulista, Tupã, v.10, n. 2, 2014.

NAPPO, M. E.; FONTES, M. A. L.; OLIVEIRAFILHO, A. T. Suficiência amostral e análise do tamanho de parcela para o estudo da regeneração natural do sub-bosque de povoamentos homogêneos de Mimosa scabrella Benth., em área minerada, em Poços de Caldas-MG. Revista Árvore, Viçosa, v.23, n.4, p.443-453, 1999.

PEREIRA, J. A. V.; DA SILVA, J. B. Detecção de focos de calor no estado da Paraíba: um estudo sobre as queimadas. Revista geográfica acadêmica, Paricarana, v. 10, n. 1, p. 5-16, 2016.

PONZONI, F. J.; SHIMABUKURO, Y. E. Sensoriamento Remoto no Estudo da Vegetação. São José dos Campos, SP: A. Silva Vieira Ed., 2010.

RODRIGUES, R. R.; LEITÃO-FILHO, H. F. Matas ciliares: conservação e recuperação. São Paulo: Edusp/Fapesp, 2000. p.289-312.

ROUSE, J.W.; HAAS, R.H.; SCHELL, J.A.; DEERING, D.W. Monitoring vegetation systems in the great plains with ERTS. In: Earth Resources Technology Satellite-1, Proceedings, Washington, v.1, p. 309-317, 1973.

SCOLFORO, J. R. S.; OLIVEIRA, A. D.; DAVIDE, A. C., MELLO, J. M.; ACERBI JUNIOR, F. W. Manejo Sustentável 
da Candeia: o caminhar de uma nova experiência em Minas Gerais. Lavras: Editora UFLA, 2012. p. 19-27.

SCOLFORO, J. R. S.; DAVIDE A. C.; OLIVEIRA; A. D.; SILVA, C. P. C.; ACERBI JÚNIOR, F.W.; ANDRADE, I. S. O Manejo da Candeia Nativa. Lavras: Editora UFLA, 2008.

SILVA, L.; COSTA FILHO, J. F., LIMA, E. R. V.; ALMEIDA, H. A. Análise do Albedo e do Índice de Vegetação da Diferença Normalizada (NDVI) em uma Bacia Hidrográfica, usando o SEBAL - Surface Energy Balance Algorithm for Land; In: XIII SBGFA, 54, 2009.

QUN, D.; HUIZHI, L. Seven years of carbon diaoxide exchange over a degraded grassland and a cropland with maize ecosystems in a semiarid area of China. Agriculture, Ecosystems and Environments, Zurich, v.173, p.1-12, 2013.

TOMZHINSKI, G. W; COURA, P. H. F; FERNANDES, M. C. Avaliação da Detecção de Focos de Calor por Sensoriamento Remoto para o Parque Nacional do Itatiaia. Biodiversidade Brasileira, Brasília-DF, v 1, n 2, p. 201-211, 2011

WULDER, M. A.; FRANKLIN, S. E. Understanding forest disturbance and spatial pattern: remote sensing and GIS approaches. New York: CRC Press, 2006. 